\section{Mission science}

\section{Roy Gibson}

Launching Europe: An Ethnography of European Cooperation in Space Science. By Stacia E. Zabusky. Princeton University Press: 1995. Pp. 261. \$49.50, £37.50 (hbk); \$17.95, £14.95 (pbk).

International Cooperation in Space: The Example of the European Space Agency. By Roger M. Bonnet and Vittorio Manno. Harvard University Press: 1994. Pp. 163. $\$ 39.95$, £24.95.

THE title of Stacia Zabusky's Launching Europe and its cover illustration of a computer-designed satellite obscure the threat contained in the subtitle: An Ethnography of European Cooperation in Space. Readers can safely traverse the book's pages ingenuity in inventing a case for new allowances, but a request for danger money would really be breaking new ground. Nor would the author's hosts be likely to share her view that the practice of working together on a scientific satellite project is considered a "sacred duty".

The anthropologist Raymond Firth, of 'malay Fishermen' fame, taught that such ethnographic studies should aim to help outsiders to interact more effectively (and less intrusively) with the group being studied and also help at least some of the members of the group to understand how they might most easily improve their lot. Zabusky's book does neither, and it is a relief to turn to one that really does cover the ground its title announces: International Cooperation in Space. Roger Bonnet has for some years been the science director at ESA, and as such is directly responsible for the space-science department. $\mathrm{He}$ is a well known and

के respected scientist, with a long involvement with European scientific cooperation. Vittorio Manno is largely a product of ESA and its predecessor, the European Space Research Organization, and has several decades of experience both as a practising space scientist and in the corridors of space-science power.

The outcome of their cooperation is a very readable look at how European space scientists started their successful collaboration, not only between scientific groups in Western Europe, but also with scientists in North America, Russia, Japan and a string of other countries. Their first-hand account of the political and financial (and occasionally scientific) vicissitudes - as seen from Europe - is as High hopes: ESA's first Ariane 4 rocket just before its launch in 1988.

without fear of increasing their understanding of the problems of 'launching' either European space or European space science. A few readers will perhaps be either sufficiently knowledgeable or sufficiently charitable to regard the book as a useful contribution to anthropology, but to those familiar with the space-science community, the mixture of melodrama and mysticism does not ring true. "Working on the edge of death is simultaneously exciting and terrifying", concludes the author, after nearly a year observing the workings of the space-science department at the European Space Agency's technical establishment in the Netherlands. This may well be true, but it is grotesquely out of place in a study of the space-science community. ESA staff have never lacked involve factors that go far beyond the competence of space agencies. Increasingly, politics, economics, industrial policy and other 'non-space' matters have greater weight than purely space considerations. It is not surprising, therefore, that Bonnet and Manno's analysis of this wider subject is less satisfying than the chapters on space science, where their obvious competence shines through.

International Cooperation in Science is nonetheless a book to read and even to buy. It makes a particularly effective antidote to the toxic effects that Zabusky's book might produce on sensitive souls such as this reviewer.

Roy Gibson, formerly director general of the European Space Agency, is at Residence Les Hespérides, 51 Allée Jean de Beins, Montpellier 34000, France.

\section{Cure thyself}

\section{Anthony Storr}

Cultures of Healing: Correcting the Image of American Mental Health Care. By Robert T. Fancher. W. H. Freeman: 1995. Pp. 355. \$23.95, £16.95 (hbk).

"THE distance between what we know and what we wish we knew is too great to bear, and we fill it with believing." Robert T. Fancher, who has a PhD in philosophy and who has worked in public-policy analysis, became disillusioned with both. Philosophy seemed to him arid, and the so-called 'scientific studies' on which public policymaking was based turned out to be promoting particular ideologies rather than being objective. Fancher then trained as a psychotherapist and practises in New York city. He has brought his critical, sceptical eye to bear on the assumptions about human nature that underlie the practice of psychotherapy. In doing so, he has written a stimulating and controversial book.

Fancher's concept of 'mental health care' is limited. Although he has chapters on the history of psychiatry, he is little concerned with contemporary treatment of the major psychoses such as schizophrenia and manic-depressive illness and omits any consideration of mental handicap, Alzheimer's disease, drug-related problems, alcoholism or any of the many other disorders requiring specialized psychiatric treatment or care in institutions. For Fancher, modern 'mental health care' is psychotherapy. Today, on both sides of the Atlantic, many thousands of people seek help from psychotherapists because they are distressed and have 'problems in living'. Different schools of psychotherapy each claim validity. Fancher's concern is with examining the unacknowledged premises supporting these claims. The 